\title{
Assessing utility and completeness of information transmission during emergency department transfers
}

\author{
Jason J. Lewis ${ }^{*}$, David W. Schoenfeld and Alden Landry
}

\begin{abstract}
Background: The transfer of patients from community emergency departments to tertiary care centers is a daily occurrence in the practice of emergency medicine, but the completeness of medical data in the transfer documentation is a relatively unstudied area. The goal of this study was to evaluate the completeness of information transmitted in the transfer documentation between transferring and accepting institutions and its perceived value at the receiving tertiary center on medical management.

Methods: Prospective, observational, and convenience sample survey study at a tertiary referral center in Boston, MA.

Results: A total of 100 surveys were completed during the 2-month study period. The presence of the radiology report and the provider note was most important in physician assessment of utility of the transfer packet for subsequent care of patients, yet these were the most commonly missing items (31.1\% and $21 \%$ respectively). Other common missing data were medication administration records, nursing notes, and laboratory results.

Conclusions: Medical data is absent in $15-31 \%$ of patients transferred from a community ED to a tertiary center. Provider notes and radiology reports were assessed as having the most utility to the receiving physicians.
\end{abstract}

Keywords: Transfer documentation, Emergency department transfer, Medical data transfer

\section{Background}

The transfer of patients from one emergency department (ED) to another is a common occurrence. Typically, these occur from community hospitals to larger medical centers for specialized care. Federal laws, including the Emergency Medical Treatment and Labor Act (EMTALA), govern the logistics of transfers requiring direct communication between the sending and receiving hospitals, as well as sending relevant records and imaging. However, there is no standard for the transfer of patients' clinical information between EDs.

While there have been a number of studies investigating the transfer of medical information at inpatient discharge [1-3], nursing home and extended care facilities (ECF) to ED transfers [4-8] as well as hand-off between residents [9], there are few studies of the transfer of data between EDs. Prior studies on inpatient

\footnotetext{
* Correspondence: jlewis@bidmc.harvard.edu

Department of Emergency Medicine, Beth Israel Deaconess Medical Center, One Deaconess Road, Rosenberg Building 2, Boston, MA 02215, USA
}

discharge packets found $29.7 \%$ did not include all of the information mandated by the Joint Commission [1]. Another study found that on inpatient discharge to home care, $31 \%$ of patients had incomplete nursing paperwork [2]. While this study did not account for verbal sign-out, this does not preclude the necessity of written discharge documentation and increases the opportunity for error.

Similarly, a Cochrane review of a hospitalist to primary care physician (PCP) discharge communication found that a summary was available in only $12-34 \%$ [3]. Direct communication occurred in only $3-20 \%$. Moreover, diagnostic test results were missing in $33-63 \%$, treatment and hospital course in $7-22 \%$, and tests results pending at the time of discharge were missing in $65 \%$ of cases [3].

A recent retrospective study limited to general surgery patients being transferred for surgical evaluation illustrated a lack of completeness of written communication but did not investigate the utility of transferred information [10]. Additionally, it was limited to a small subset of 
transfers and the retrospective review of records may not reflect real-time availability and therefore utility of the written communications. In this study, we aimed to prospectively evaluate what information is transferred between EDs across all ED-to-ED transfers and its effect on the accepting teams' management.

\section{Methods}

This was a prospective, observational, and convenience sample survey study of transfer documentation conducted at an urban, academic adult tertiary medical center in Boston, MA. Transfers to our facility were initiated by the transferring facility, calling our ED, and speaking to an attending physician who subsequently accepted or declined the transfer without specific discussion regarding information to be transferred. All transfers from any ED to the study center ED were eligible for enrollment during the 2-month study period. For each ED-to-ED transfer, residents caring for the patient were asked to complete a ten-question survey about the information sent by the referring $\mathrm{ED}$ and available to the treating physicians at the receiving ED (Fig. 1). A "call-in" is a brief electronic summary of the patient's illness and care at the referring facility, which is typically entered into the receiving hospital's ED information system by the individual accepting the transfer call and linked to the patient record but is not required.

The perceived utility of the information provided was assessed using a five-point Likert scale (Fig. 1). Ratings were dichotomized into useful $\geq 4$ or not useful $<4$. A logistic regression analysis was performed to evaluate for which data present was most likely to result in a favorable review of the transfer documentation. This study was approved by the Institutional Review Board at our institution.

\section{Results}

One-hundred surveys were completed. Twenty-four percent of transfers were from hospitals directly affiliated with the receiving hospital and staffed by the same physician group. The odds of receiving physicians assessing the transfer documentation as useful was increased 1.53 times, (95\% CI $0.67-2.61, p<0.01)$ if the provider note was present, and 1.39 times, $(95 \%$ CI $0.58-2.44, p<0.01)$ if the radiology report was present. These were the most commonly missing (Table 1). None of the other studied factors had a statistically significant impact on the physicianassessed usefulness of the transfer documentation. Laboratory tests and radiology imaging were not performed in three and ten cases, respectively, and were therefore

\begin{tabular}{|l|l|l|l|}
\hline & Present & Absent & Not Applicable a $^{\text {a }}$ \\
\hline Reason for Transfer & & & \\
\hline Electronic Call-In & & & \\
\hline $\begin{array}{l}\text { Electronic Medical Record } \\
\text { (EMR) }\end{array}$ & & & \\
\hline Nursing Notes & & & \\
\hline $\begin{array}{l}\text { Medication Administration } \\
\text { Record }\end{array}$ & & & \\
\hline Provider Note & & & \\
\hline Laboratory Tests & & & \\
\hline Radiology Reports & & & \\
\hline Radiology Imaging & & & \\
\hline Demographics & & & \\
\hline
\end{tabular}

I felt the transfer documentation provided was complete and was useful for the care of my patient:

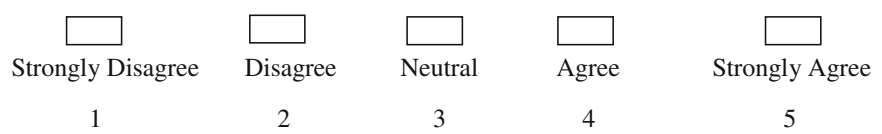

a "Not Applicable" referred to tests/studies that were not performed at the outside hospital and therefore would not be included in the transfer packet.

Fig. 1 Data collection survey and utility score of transfer documentation between two emergency departments 
Table 1 Missing transfer data between two emergency departments

\begin{tabular}{ll}
\hline Category & $\%$ Missing \\
\hline Electronic medical record linked to our system & $87(87 / 100)$ \\
Radiology report & $31.1(28 / 90)$ \\
Provider note & $21(21 / 100)$ \\
Medication administration record & $20(20 / 100)$ \\
Laboratory results & $17.5(17 / 97)$ \\
Nursing notes & $15(15 / 100)$ \\
Electronic call-In & $14(14 / 100)$ \\
Demographics & $12(12 / 100)$ \\
Radiology imaging & $4.4(4 / 90)$ \\
Reason for transfer & $2(2 / 100)$ \\
\hline
\end{tabular}

marked "not applicable" (Table 1). Overall, 68\% of cases had at least one component missing.

\section{Discussion}

The importance of complete transfer documentation between EDs is integral to the smooth transition of care; however, as demonstrated in this study, transmission of key information is inadequate. Provider note and radiology report are viewed by physicians as the most important to aid in the transition of care; however, these are most frequently missing in the transfer documentation. The improved transition of care with appropriate documentation of medical results reduces hospital costs by avoiding redundant testing and likely helps reduce medical error [11].

Our results are similar to previous studies of hospital discharge paperwork $[1,2]$, as well as nursing home and ECF-to-ED transfers [4-8]. Lack of documentation has been found to increase time in ED and investigative studies in patients with altered mental status [8]. Additionally, ED length of stay (LOS) has been shown to be increased by investigative studies [12, 13] and physician hand-off [14]. For every five additional lab tests ordered, the median ED LOS increases by 10 min [12]. Moreover, lab turnaround times affect time to disposition, with every 30-min interval of lab turnaround time leading to 17 min additional LOS [12]. Compared with no testing, admitted patients with any test performed in the ED had a 49.5-min increase in LOS [13]. While our study did not look directly at LOS of transferred patients, it stands to reason that lack of complete transfer documentation may lead to repeat testing and therefore longer LOS. Furthermore, $4.4 \%$ of transferred cases did not include the radiology imaging, which may not only impact LOS but also may lead to repeat radiologic studies and unnecessary radiation exposure.

Given the similarities of findings between our study, ECF-to-ED transfers, and discharged patients to ECFs and PCPs, the question remains how best to improve the transmission of critical information during the transition of care. Gandara et al. organized wholesale changes in the umbrella corporation governing the five major hospitals in its study [1]. These included improvements to the computer-based discharge summaries to include prompts or auto-importation for required documentation, creation of discharge templates, peer review, and feedback, as well as mandated training for clinicians on proper discharge summaries [1]. While all of these methods may not be feasible in an ED setting, information technology (IT) should be at the forefront.

A standardized role of healthcare IT and electronic medical records (EMR) in hand-offs within the hospital

Patient:

DOB:

Reason for Transfer:

Transfer Hospital:

\begin{tabular}{|l|l|l|}
\hline & Included & Not applicable \\
\hline Nurses Notes & & \\
\hline $\begin{array}{l}\text { Medication Administration } \\
\text { Record }\end{array}$ & & \\
\hline Provider Note & & \\
\hline Lab Results & & \\
\hline Radiology Report & & \\
\hline $\begin{array}{l}\text { Radiology Imaging } \\
\text { (electronic or disc) }\end{array}$ & & \\
\hline Demographic Sheet & & \\
\hline
\end{tabular}

Fig. 2 Standardized transfer packet form for ED-to-ED transfers 
would markedly improve safety and decrease the loss of information at patient hand-off [9]. Linking of EMRs between transferring facilities could decrease the amount of lost data. During our study period, two of the transferring facilities shared EMRs with the medical center. While $24 \%$ of cases were transferred from these institutions, EMR was available in only $13 \%$. This may have been related to a technical delay in uploading into the EMR to be used by the accepting team or delayed linking of the patient's information within the computer system. Both of these issues could be addressed by the IT department. Likewise, the adoption of a cloud-based radiology imaging program would ensure that all imaging is available.

While it may not be feasible for an accepting facility to routinely provide feedback to the transferring facility on the quality and completeness of the transfer documentation, as implemented in Gandara et al.'s study, it is possible to create a standardized transfer checklist to be filled out by the transferring institution in order to ensure all information available is transmitted. The use of a standardized ECF-to-ED transfer sheet containing 11 essential data elements increased the amount of data provided to the ED [5]. Although it was included in only one third of transfers, it resulted in successful documentation in nearly all cases [5]. Another study developed forms for nursing home transfers, which ED staff found to be helpful in $98 \%$ of cases and more time-efficient [7]. The main critique from physicians was that the form was not always completed [7]. A standardized ED-to-ED transfer form, proposed in Fig. 2, ensuring both the provider note and radiology reports are included could improve the transfer documentation packet received by accepting facilities, thereby decreasing the time to disposition and overall LOS.

\section{Limitations}

Our study is limited by both its small sample size and single study site. This was a convenience sample study design during which residents voluntarily filled out a survey. Multiple subjects may not have been included due to resident preference. There is no fully accurate way to determine the exact number of transfers that occurred during the 2-month study period. Inter-rater reliability was not measured between residents filling out the surveys, and it is possible that results were biased by specific individuals completing or not completing surveys. Finally, the utility score is based on a subjective decision that may not be standardized among respondents.

\section{Conclusions}

Provider notes and radiology reports are the most useful components in transfer documentation, yet are frequently missing. Important clinical data is absent from the transfer documentation packet in $15-31 \%$ of transfers. Imaging was not included in $4.4 \%$ of transferred patients, which can lead to repeat radiologic studies and unnecessary exposure to ionizing radiation. In addition to the direct impact, this unnecessary testing may lead to increased ED LOS for transferred patients and impact overall ED LOS. There is an opportunity for significant improvement in transfer documentation, which could be aided by new IT developments allowing increased sharing of electronic records, as well as utilizing a standardized checklist to ensure transmission of valuable clinical information.

\section{Abbreviations}

ECF: Extended care facility; ED: Emergency department; EMR: Electronic medical record; EMTALA: Emergency Medical Treatment and Labor Act; IT: Information technology; LOS: Length of stay; PCP: Primary care physician

\section{Acknowledgements}

The authors would like to thank Micheal Buggia, MD, for his contribution to the initial data collection.

Funding

Not applicable

\section{Availability of data and materials}

The datasets used and/or analyzed during the current study are available from the corresponding author on reasonable request.

\section{Authors' contributions}

$J$ contributed to creating the data collection survey, collecting and analyzing the data and writing the manuscript. DS performed statistical analysis and contributed to the writing of the manuscript. AL supervised the study, contributed to study design, and contributed to the writing of the manuscript. All authors read and approved the final manuscript.

\section{Ethics approval and consent to participate}

This study was approved by the Institutional Review Board at Beth Israel Deaconess Medical Center. This was a convenience sample survey study in which participants voluntarily filled out a survey regarding transfer documentation and did not require consent to participate.

\section{Consent for publication}

Not applicable. There is no individual data or personal health information reported in this study that requires consent to publish.

\section{Competing interests}

The authors declare that they have no competing interests.

\section{Publisher's Note}

Springer Nature remains neutral with regard to jurisdictional claims in published maps and institutional affiliations.

Received: 18 September 2018 Accepted: 10 October 2018 Published online: 29 October 2018

References

1. Gandara E, Moniz T, Ungar J, Lee J, Chan-Macrae M, O'malley T, et al. Communication and information deficits in patients discharged to rehabilitation facilities: an evaluation of five acute care hospitals. J Hosp Med. 2009;4(8):E28-33.

2. Olsen RM, Hellzen O, Enmarker I. Nurses' information exchange during older patient transfer: prevalence and association with patient and transfer characteristics. Int J Integr Care. 2013;13(Jan-Mar):1-10. 
3. Kripalani S, LeFevre F, Phillips CO, Williams MV, Basaviah P, Baker DW. Deficits in communication and information transfer between hospital-based and primary care physicians: implications for patient safety and continuity of care. JAMA. 2007;297(8):831-41.

4. Terrell KM, Miller DK. Challenges in transitional care between nursing homes and emergency departments. J Am Med Dir Assoc. 2006;7(8):499-505

5. Terrell KM, Brizendine EJ, Bean WF, Giles BK, Davidson JR, Evers S, et al. An extended care facility-to-emergency department transfer form improves communication. Acad Emerg Med. 2005;12(2):114-8.

6. Jones JS, Dwyer PR, White LJ, Firman R. Patient transfer from nursing home to emergency department: outcomes and policy implications. Acad Emerg Med. 1997;4(9):908-15

7. Madden C, Garret J, Busby-Whitehead J. The interface between nursing homes and emergency departments: a community effort to improve transfer of information. Acad Emerg Med. 1998:5(11):1123-6.

8. Morphet J, Griffiths DL, Innes K, Crawford K, Crow S, Williams A. Shortfalls in residents' transfer documentation: challenges for emergency department staff. Australas Emerg Nurs J. 2014;17(3):98-105.

9. Koppel $\mathrm{R}$, Telles $\mathrm{J}$. Role of healthcare information technology in handoffs. In: Courtney KL, et al., editors. Enabling health and healthcare through ICT. USA: IOS Press; 2013. p. 21-7.

10. Harl FNR, Saucke MC, Greenberg CC, Ingraham AM. Assessing written communication during interhospital transfers of emergency general surgery patients. J Surg Res. 2017;214:86-92.

11. Coleman EA, Berenson RA. Lost in transition: challenges and opportunities for improving the quality of transitional care. Ann Intern Med. 2004;141(7):533-6.

12. Li L, Georgiou A, Vecellio E, Eigenstetter A, Toouli G, Wilson R, et al. The effect of laboratory testing on emergency department length of stay: a multihospital longitudinal study applying a cross-classified random-effect modeling approach. Acad Emerg Med. 2015;22(1):38-46.

13. Kocher KE, Meurer WJ, Desmond JS, Nallamothu BK. Effect of testing and treatment on emergency department length of stay using a national database. Acad Emerg Med. 2012;19(5):525-34.

14. Bashkin O, Caspi S, Haligoa R, Mizrahi S, Stalnikowicz R. Organizational factors affecting length of stay in the emergency department: initial observational study. Isr J Health Policy Res. 2015;4(1):38.

Ready to submit your research? Choose BMC and benefit from:

- fast, convenient online submission

- thorough peer review by experienced researchers in your field

- rapid publication on acceptance

- support for research data, including large and complex data types

- gold Open Access which fosters wider collaboration and increased citations

- maximum visibility for your research: over $100 \mathrm{M}$ website views per year

At $\mathrm{BMC}$, research is always in progress.

Learn more biomedcentral.com/submissions 